\title{
CpG Motifs in Bacterial DNA Cause Inflammation in the Lower Respiratory Tract
}

David A. Schwartz, ${ }^{* \Uparrow}$ Timothy J. Quinn, ${ }^{*}$ Peter S. Thorne, ${ }^{\S}$ Sadath Sayeed, ${ }^{\ddagger}$ Ae-Kyung Yi, ${ }^{\circ}$ and Arthur M. Krieg ${ }^{\ddagger \mid \uparrow}$

*Pulmonary, Critical Care, and Occupational Medicine Division and ${ }^{\ddagger}$ Rheumatology Division, Department of Internal Medicine; ${ }^{\S}$ Division of Occupational and Environmental Health, Department of Preventive Medicine; "Interdisciplinary Immunology Program; and "IDepartment of Veterans Affairs Medical Center, The University of Iowa, Iowa City, Iowa 52242

\section{Abstract}

Since unmethylated $\mathrm{CpG}$ motifs are more frequent in DNA from bacteria than vertebrates, and the unmethylated $\mathrm{CpG}$ motif has recently been reported to have stimulatory effects on lymphocytes, we speculated that bacterial DNA may induce inflammation in the lower respiratory tract through its content of unmethylated $\mathrm{CpG}$ motifs. To determine the role of bacterial DNA in lower airway inflammation, we intratracheally instilled prokaryotic and eukaryotic DNA in $\mathrm{C} 3 \mathrm{H} / \mathrm{HeBFEJ}$ mice and performed whole lung lavage $4 \mathrm{~h}$ after the exposure. Heat denatured, single stranded Escherichia coli genomic DNA (0.06 ng endotoxin/ $\mu$ g DNA) was compared to heat denatured, single stranded calf thymus DNA (0.007 endotoxin/ $\mu$ g DNA). $10 \mu \mathrm{g}$ of bacterial DNA, in comparison to $10 \mu \mathrm{g}$ of calf thymus DNA, resulted in a fourfold increase in the concentration of cells $(P=0.0002)$, a fivefold increase in the concentration of neutrophils $(P=$ 0.0002 ), a 50-fold increase in the concentration of TNF- $\alpha$ $(P=0.001)$, and a fourfold increase in the concentration of both IL-6 $(P=0.0003)$ and macrophage inflammatory protein-2 $(P=0.0001)$ in the lavage fluid. Importantly, instillation of $0.60 \mathrm{ng}$ of $E$. coli LPS resulted in a negligible inflammatory response. To test whether the stimulatory effects of bacterial DNA are due to its unmethylated $\mathrm{CpG}$ dinucleotides, we methylated the bacterial DNA and also prepared 20 base pair oligonucleotides with and without CpG motifs. In comparison to instillation of untreated bacterial DNA, methylation of the bacterial DNA resulted in a significant reduction in the concentration of cells and cytokines in the lower respiratory tract. Moreover, oligonucleotides containing embedded unmethylated $\mathrm{CpG}$ motifs resulted in inflammation in the lower respiratory tract that was indistinguishable from that observed with untreated bacterial DNA. In contrast, oligonucleotides without the embedded CpG motifs or with embedded but methylated $\mathrm{CpG}$ motifs resulted in significantly less inflammation in the lower respiratory tract. The possible relevance of these data to human disease was shown by extracting and analyzing DNA in sputum from patients with cystic fibrosis (CF). Approximately 0.1 to $1 \%$ of this sputum DNA was bacterial. Intratracheal instillation of highly purified CF sputum DNA caused acute inflammation similar to that induced by bacterial DNA.

Address correspondence to David A. Schwartz, Pulmonary, Critical Care and Occupational Medicine Division, Department of Internal Medicine, The University of Iowa, Iowa City, IA 52242. Phone: 319356-8264; FAX: 319-313-8973; E-mail: david-schwartz@uiowa.edu

Received for publication 1 July 1996 and accepted in revised form 3 April 1997.

The Journal of Clinical Investigation

Volume 100, Number 1, July 1997, 68-73
These findings suggest that bacterial DNA, and unmethylated $\mathrm{CpG}$ motifs in particular, may play an important pathogenic role in inflammatory lung disease. (J. Clin. Invest. 1997. 100:68-73.) Key words: DNA • CpG dinucleotides $\bullet$ infection $\bullet$ pulmonary disease $\bullet$ lung inflammation

\section{Introduction}

The etiologic factors leading to pulmonary inflammation are often unknown and the ensuing pathogenesis is complex. Although bacteria and specific environmental exposures can cause extensive lung disease with profound inflammation, many forms of inflammatory lung disease are idiopathic and do not have a specific etiology. For instance, most cases of pulmonary fibrosis or acute respiratory distress syndrome (ARDS) do not have an identifiable etiology. Similarly, the events or triggers initiating and promoting lung inflammation in patients with cystic fibrosis $(\mathrm{CF})^{1}$ have not been clearly defined. Given these examples, it is logical to speculate that pulmonary inflammation, in most cases, results from the host's response to a variety of environmental stimuli. The lung provides a unique interface with the environment; breathing $\sim 20,000$ liters of air each day which is potentially contaminated with particles, gases, microorganisms, and allergens. Since the lung is continuously exposed to microorganisms, an obvious environmental cause of lung inflammation could be the unique components of microorganisms that distinguish these cells from eukaryotic cells.

Recently, we (1) have found that bacterial DNA and certain oligonucleotides containing unmethylated $\mathrm{CpG}$ dinucleotides in particular base contexts ( $\mathrm{CpG}$ motifs) have stimulatory effects on murine and human lymphocytes in vitro and murine lymphocytes in vivo. These stimulatory effects include triggering $\mathrm{B}$ cell proliferation, resistance to apoptosis, and release of IL-6 and IL-12 (1, 2-5), natural killer (NK) cell secretion of IFN- $\gamma$ and increased lytic activity $(2,6-9)$; and monocyte/macrophage secretion of IFN- $\alpha / \beta$, IL-6, IL-12, GMCSF, chemokines, and TNF- $\alpha$ (Krieg, A.M., unpublished data; 9a). Eukaryotic DNA or methylated bacterial DNA or CpG oligonucleotides are nonstimulatory.

CpG motifs are at least 20-fold more common in bacterial than vertebrate DNA for three reasons. First, vertebrate DNA shows $\mathrm{CpG}$ suppression with only one-third to one-fourth of the $\mathrm{CpG}$ dinucleotides predicted based on random base utilization (10). Second, $\sim 80 \%$ of the $\mathrm{CpG}$ dinucleotides present in vertebrate DNA are methylated at the 5 position of the cytosine (10). Third, the CpG in the vertebrate genome are usually in a nonstimulatory sequence context: they are most frequently preceded by a $\mathrm{C}$, which eliminates or severely reduces the stimulatory effects on B cells, NK cells, and monocytes (5, 7;

1. Abbreviations used in this paper: CF, cystic fibrosis; MIP-2, macrophage inflammatory protein-2; NK, natural killer. 
Krieg, A.M., unpublished data). The potent immunological response to unmethylated $\mathrm{CpG}$ motifs suggests that the vertebrate immune system recognizes this molecular pattern characteristic of bacterial DNA as a "danger signal," and activates appropriate immune responses to defend against the potentially adverse effects of microorganisms (reviewed in reference 11).

Since DNA is readily taken up by lymphocytes (12-14), it is logical to hypothesize that bacterial DNA and specifically unmethylated CpG motifs are capable of causing inflammation in the lower respiratory tract and may contribute to disease progression and morbidity in some forms of lung disease. To determine the possible role of bacterial DNA and unmethylated $\mathrm{CpG}$ motifs in lower airway inflammation, we intratracheally instilled prokaryotic DNA, eukaryotic DNA, and unique 20 base pair oligonucleotides in mice and performed whole lung lavage $4 \mathrm{~h}$ after the exposure. Our results indicate that bacterial DNA, and unmethylated $\mathrm{CpG}$ motifs in particular, may play an important pathogenic role in inflammatory lung disease.

\section{Methods}

Animals. C3H/HeBFEJ male mice (Jackson Laboratories, Bar Harbor, ME) were obtained at $6 \mathrm{wk}$ of age and used within 2 wk. Measured weights on the day of exposure were $25.02 \pm 0.20$ grams. All animal care and housing requirements set forth by the National Institutes of Health Committee on Care and Use of Laboratory Animals of the Institute of Laboratory Animal Resources were followed, and animal protocols were reviewed and approved by the Institutional Animal Care and Use Committee. Mice were maintained in wood-chip bedding (Northeastern Product, Warrensberg, NY), with food (Formulab Chow 5008; PMI, Richmond, IN) and water supplied ad libitum.

Genomic DNA. Escherichia coli (strain B) DNA and calf thymus DNA were purchased from Sigma Chemical Co. (St. Louis, MO) and purified by extraction with phenol/chloroform/isoamyl alcohol (25:24:1) and ethanol precipitation. The LPS level in E. coli and calf thymus DNA was $\leq 0.06 \mathrm{ng} / \mathrm{mg}$ of DNA by Limulus assay. Heat denatured (single-stranded) genomic DNA was used in all experiments. E. coli DNA was methylated with $2 \mathrm{U}$ CpG methylase (New England Biolabs, Inc., Beverly, MA) per $\mu \mathrm{g}$ DNA for $18 \mathrm{~h}$ at $37^{\circ} \mathrm{C}$. Endotoxin concentrations in the E. coli and calf thymus genomic DNA were assayed using the endpoint chromogenic Limulus amoebocyte lysate assay (QCL-1000; Whittaker Bioproducts, Walkersville, MD) with sterile pyrogen-free labware and a temperature-controlled microplate block and microplate reader $(405 \mathrm{~nm})$.

Cystic fibrosis sputum DNA. After giving informed consent, patients with $\mathrm{CF}$ and chronic clinical pulmonary inflammation (sputum production) provided sputum samples. All patients were chronic carriers of Pseudomonas aeruginosa, with or without a wide variety of other organisms. The CF sputum samples were processed by: homogenization in RNAse extraction buffer (10 mM Tris [pH 8.0], $0.1 \mathrm{M}$ EDTA, $20 \mu \mathrm{g} / \mathrm{ml}$ RNAse, $0.5 \%$ SDS) for $1 \mathrm{~h}$ at $37^{\circ} \mathrm{C}$, followed by addition of proteinase $\mathrm{K}$ to $100 \mu \mathrm{g} / \mathrm{ml}$, and digestion for $3 \mathrm{~h}$ at $50^{\circ} \mathrm{C}$. The samples were then extracted with salt saturated phenol, followed by phenol/chloroform and chloroform. DNA was precipitated with sodium acetate, resuspended in Tris-EDTA, and redigested with proteinase $\mathrm{K}$ followed by reextraction with phenol three times, followed by reprecipitation. DNA purity was determined through UV spectrophotometry, analysis of DNA for endotoxin contamination performed, and removal of endotoxin using electrostatically charged filters, as described previously (15).

The calculation of the percentage of CF DNA which consists of bacterial sequences was done with a semiquantitative PCR technique. PCR primers (5' GAGGAAGGIGIGGAIGACGT; 3' AGICCCGI-
GAACGIATTCAC) specific for conserved regions in bacterial rDNA genes and protocol were kindly provided by Dr. C.R. Steinman (State University of New York at Stonybrook). A standard curve is generated by PCR using two and fivefold dilutions of an E. coli bacterial DNA standard over a range from $1,000 \mathrm{pg} / \mathrm{ml}$ to $1 \mathrm{pg} / \mathrm{ml}$. The amplified DNA bands are detected by ethidium bromide staining and their intensity compared to that of titered CF DNA samples on the same gel. From this it is simple to calculate the percentage of bacterial DNA within the CF sample which has been consistently 0.1 to $1.0 \%$ of the total DNA. This measure is almost certainly an underestimate of the true concentration of bacterial DNA in our samples due to the likely presence of some degraded DNA within our samples, since cleavage between primer sites will disrupt PCR amplification.

For analysis of the immune effects of $P$. aeruginosa DNA, bacterial cell pellets were kindly provided by P. Greenberg (University of Iowa, Iowa City, IA), and genomic DNA purified by the technique of Goldberg and Ohman (16), with subsequent further purification by Triton X-114 precipitation to reduce the endotoxin levels $<2.5 \mathrm{ng} / \mathrm{mg}$.

Oligonucleotides. 20 base pair oligonucleotides were synthesized with and without the embedded $\mathrm{CpG}$ motifs (Midland Certified Reagent Company; Midland, TX). These oligonucleotides contained a nuclease-resistant phosphorothioate-modified backbone, and were purified by two rounds of ethanol precipitation before use. For our studies, we selected an oligonucleotide which contained two $\mathrm{CpG}$ dinucleotides in stimulatory base contexts as defined in our prior studies for B cell, NK cell, and monocyte activation $(1,5,7)$. The in vitro immune effects of this oligonucleotide were essentially identical to those of dozens of other sequences evaluated in in vitro assays (not shown). The nonstimulatory oligonucleotide was identical to the stimulatory oligonucleotide except that the two embedded CpG motifs were modified, one appearing as an ApG motif and the other appearing as a $\mathrm{GpC}$ motif. The two synthesized oligonucleotides had the following sequences: $\mathrm{CpG}$ Oligonucleotide: ATAATCGACGTTCAAGCAAG; non-CpG oligonucleotide: ATAATAGAGCTTCAAGCAAG.

Methylation protocol. DNA was methylated as we have described previously (1) with $2 \mathrm{U}$ CpG methylase (New England Biolabs, Inc.) per $\mu \mathrm{g}$ DNA for $18 \mathrm{~h}$ at $37^{\circ} \mathrm{C}$. Methylated DNA was tested to confirm that it was completely protected against digestion with Hpa-II but not Msp-I.

Instillation protocol. Mice were lightly anesthetized with inhaled methoxyflurane (Pitman-Moore, Inc., Mundelein, IL), and placed supine with their head tilted back. The trachea was visualized under fiberoptic illumination and intubated with a 24-gauge IV catheter (Jelco, ETO sterilized, nonpyrogenic; Johnson \& Johnson Medical, Inc., Arlington, TX) that was modified by cutting off the bevel such that the needle was flush with the sheath when fully inserted. A 1-cc syringe containing $50 \mu \mathrm{l}$ of DNA or oligonucleotide solution was then attached to the catheter and used to instill the solution. The catheter was then removed and the mice were allowed to recover from the anesthesia which required about $5 \mathrm{~min}$.

Lung lavage. $4 \mathrm{~h}$ after DNA or oligonucleotide instillation, mice were killed, the chest was opened, and lungs were lavaged in situ via PE-90 tubing inserted into the exposed trachea. A pressure of $25 \mathrm{~cm}$ $\mathrm{H}_{2} \mathrm{O}$ was used to wash the lungs with $6.0 \mathrm{ml}$ of sterile pyrogen-free saline, $1 \mathrm{ml}$ at a time.

Treatment of lavage fluid. Our standard method (15) of processing the sample is as follows: immediately following lavage, the volume is noted and $15-\mathrm{ml}$ conical tubes are centrifuged for $5 \mathrm{~min}$ at $200 \mathrm{~g}$. The supernatant fluid is decanted and frozen at $-70^{\circ} \mathrm{C}$ for subsequent use. The residual pellet of cells is resuspended in HBSS (without Ca or $\mathrm{Mg}$ ). A small aliquot of the sample is taken for cell count using a hemocytometer. The cells are then spun for 5 min onto a glass slide using a cytocentrifuge. Staining is performed using a Diff Quick Stain (Baxter Scientific, Miami, FL).

Lavage fluid cytokine analysis. Lavage fluid was assayed for TNF- $\alpha$, IL-1 $\beta$, IL-6, and macrophage inflammatory protein-2 (MIP-2). $\mathrm{TNF}-\alpha$ was measured using a polyclonal antibody specific for mouse 
TNF- $\alpha$ (R \& D Systems, Minneapolis, MN) as a capture reagent in a standard sandwich ELISA. The limit for detection of this ELISA is $5.1 \mathrm{pg} / \mathrm{ml}$ of mouse TNF- $\alpha$. These results were validated against a cytotoxicity assay using the TNF-sensitive L929 fibroblast cell line (17). IL-1 $\beta$ was measured using an ELISA (Biosource International, Camarillo, CA) prepared with anti-murine IL-1 $\beta$ monoclonal antibody. The detection limit of this assay was determined to be $7 \mathrm{pg} / \mathrm{ml}$, and the antiserum used in this assay is specific for IL-1 $\beta$. IL-6 was determined by ELISA method using antibodies obtained from Pharmingen Corp. (San Diego, CA). Briefly, monoclonal capture and biotinylated detection antibodies specific for murine IL-6 were used. Immulon I plates (Dynatech Laboratories, Chantilly, VA) were coated with capture antibody and stored overnight at $4^{\circ} \mathrm{C}$. The plate was washed and blocked for $2 \mathrm{~h}$ at room temperature with $1 \times \mathrm{PBS} /$ $10 \%$ FCS $/ 0.05 \%$ Tween-20, followed by plating of samples and standards in triplicate and overnight incubation. Standards were generated using recombinant murine IL-6 (PharMingen Corp.). Detection antibodies were incubated for $1 \mathrm{~h}$. Plates then underwent 45-min incubation of avidin-horseradish peroxidase (Biorad Laboratories, Hercules, CA). Detection was achieved using $o$-Phenylenediamine Dihydrochloride (Sigma Chemical Co.) in citrate buffer with $\mathrm{H}_{2} \mathrm{O}_{2}$. MIP-2 was measured using a rat MIP-2 ELISA kit (Biosource International) containing antibodies that are cross-reactive to murine MIP-2. A standard curve was generated using recombinant murine MIP-2 generously provided by Dr. Patricia Olsen of the Chiron Corporation (Emery, CA).

Preparation of RNA and multiprobe RNase protection assay. Total RNA was extracted from lung specimens using the single-step method $(18,19)$, lysing flash frozen lung in RNA STAT-60 (Tel-Test B, Friendswood, TX). The composition of RNA STAT-60 includes phenol and guanidinium thiocyanate in a monophase solution. The lung parenchyma was homogenized in the RNA STAT-60 using a polytron homogenizer. Chloroform was added, the total RNA was precipitated from the aqueous phase by addition of isopropanol, and the total RNA was washed with ethanol and solubilized in water. After drying the pellet in a vacuum dessicator, the yield and purity of RNA was quantitated by measuring the ratio of absorbances at 260 and $280 \mathrm{~nm}$. Mini-gel electrophoresis was used to confirm the integrity of the $28 \mathrm{~s}$ and $18 \mathrm{~s}$ rRNA bands. Gene transcripts were detected using the RNase protection assay and probes as previously described (20).

Statistical analysis. Four primary comparisons were pursued in this investigation: $(a)$ the lung inflammatory response to prokaryotic (bacterial) versus eukaryotic (calf thymus) DNA; $(b)$ the lung inflammatory response to untreated prokaryotic DNA versus methylated prokaryotic DNA; $(c)$ the lung inflammatory response to an oligonucleotide containing embedded $\mathrm{CpG}$ motifs versus the response to an oligonucleotide not containing CpG motifs; and $(d)$ the inflammatory response in lower respiratory tract after instillation of an oligonucleotide containing unmethylated $\mathrm{CpG}$ motifs versus an oligonucleotide containing methylated $\mathrm{CpG}$ motifs. The inflammatory response was assessed using lavage cellularity, lavage fluid cytokine concentration, and the relative concentration of mRNA for specific cytokines in the lung parenchyma. After making sure that the data were normally distributed, statistical comparisons were made using parametric statistics including the Student's $t$ test (21).

\section{Results}

Prokaryotic DNA results in significant inflammation when compared with eukaryotic DNA. These differences are best demonstrated after intratracheal-tracheal instillation of $10 \mu \mathrm{g}$ of bacterial DNA which results in a fourfold increase in the concentration of cells lavaged from the lower respiratory tract when compared to instillation of $10 \mu \mathrm{g}$ of calf thymus DNA (Fig. 1). Moreover, in comparison to calf thymus DNA, exposure to $10 \mu \mathrm{g}$ of bacterial DNA resulted in a profound increase

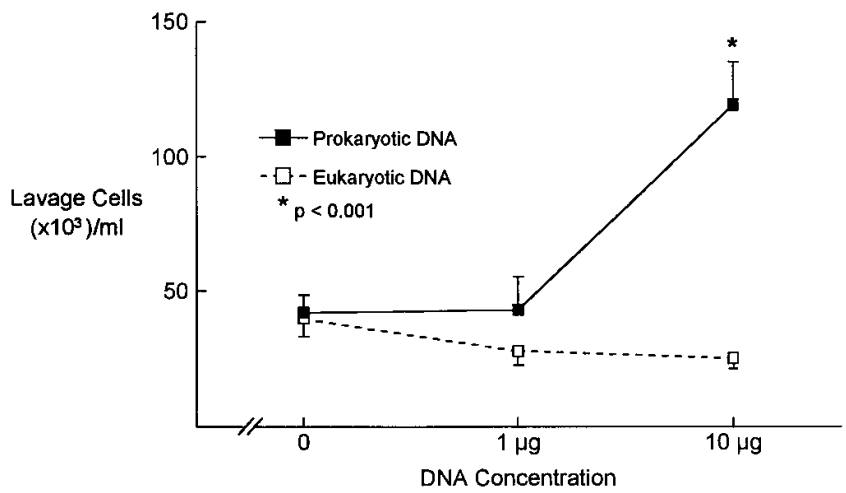

Figure 1. Concentration of total cells in the whole lung lavage fluid intratracheal instillation of prokaryotic (bacterial) DNA (solid squares) and eukaryotic (calf thymus) DNA (open squares). Error bars, SE.

in the concentration of polymorphonuclear leukocytes, TNF- $\alpha$, IL-6, and MIP-2 in the lavage fluid (Fig. 2). Interestingly, no significant increases were seen in the concentration of IL- $1 \beta$ in the lavage fluid after exposure to bacterial DNA.

Although bacterial DNA has approximately a 10-fold excess of endotoxin (0.06 $\mathrm{ng}$ endotoxin $/ \mu \mathrm{g}$ bacterial DNA) in comparison to calf thymus DNA (0.007 ng endotoxin/ $\mu \mathrm{g}$ calf thymus DNA), the differences in the inflammatory response in the lower respiratory tract were not due to endotoxin. Instillation of $0.60 \mathrm{ng}$ of $E$. coli lipopolysaccharide resulted in a negligible inflammatory response in the lower respiratory tract (Fig. 3).

Since unmethylated $\mathrm{CpG}$ motifs are more frequent in DNA from bacteria than vertebrates, and the unmethylated $\mathrm{CpG}$ motif has been reported to have immune stimulatory effects, we speculated that the unmethylated $\mathrm{CpG}$ motif was responsible for bacterial DNA induced inflammation in the lower respiratory tract. To test this hypothesis, we compared the inflammatory response in the lower respiratory tract between untreated and methylated bacterial DNA. Our results (Fig. 4) indicate that methylation of bacterial DNA results in a marked reduction in the concentration of cells, polymorpho-

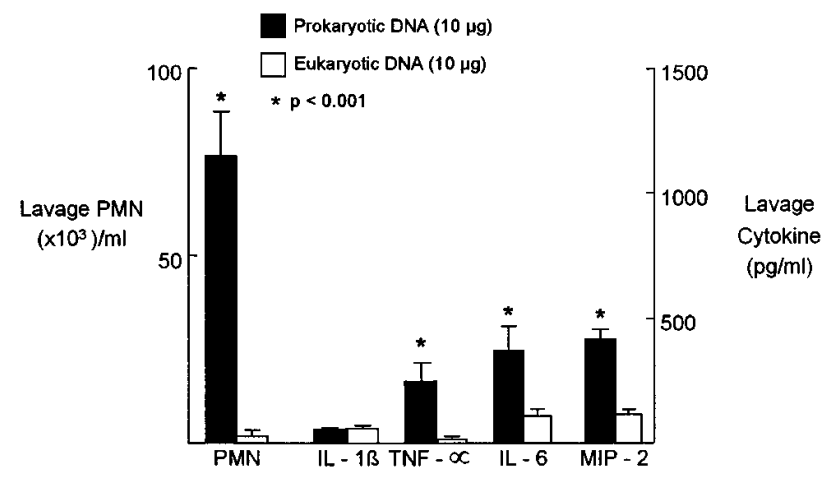

Figure 2. Concentration of total PMN and specific cytokines ( $I L-1 \beta$, $T N F-\alpha, I L-6$, and $M I P-2)$ in the whole lung lavage fluid after intratracheal instillation of prokaryotic (bacterial) DNA (solid bars) and eukaryotic (calf thymus) DNA (open bars). Error bars, SE. 


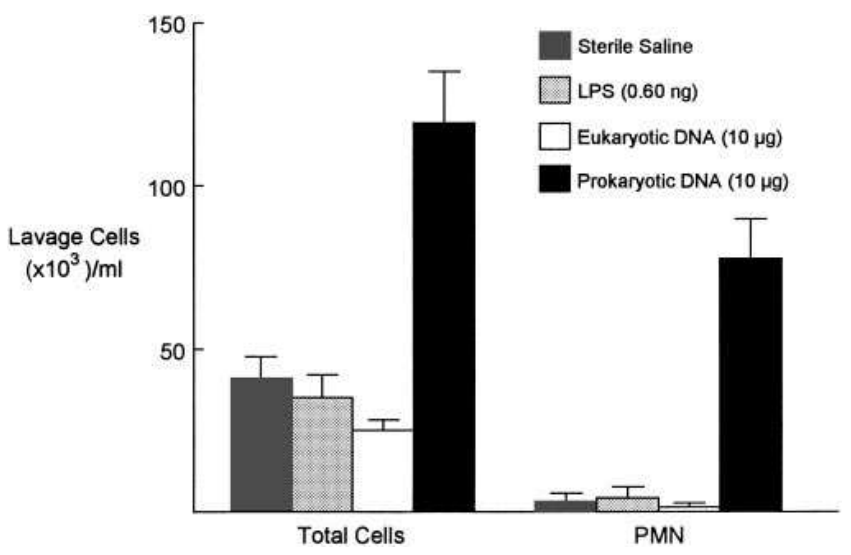

Figure 3. Concentration of total cells and PMN in the whole lung lavage fluid after intratracheal instillation of buffered sterile saline (striped bar), LPS (stippled bar), eukaryotic (calf thymus) DNA (open bar), and prokaryotic (bacterial) DNA (solid bar). Error bars, SE.

nuclear leukocytes, and cytokines in the lavage fluid in comparison to untreated bacterial DNA.

To further assess the effect of unmethylated $\mathrm{CpG}$ motifs, we prepared 20 base pair oligonucleotides with and without embedded CpG motifs. While instillation of $10 \mu \mathrm{g}$ of an oligonucleotide containing embedded unmethylated $\mathrm{CpG}$ motifs resulted in inflammation in the lower respiratory tract that was indistinguishable from that observed with $10 \mu \mathrm{g}$ of untreated bacterial DNA, instillation of an oligonucleotide without the embedded CpG motifs resulted in significantly less inflammation (Fig. 5). Finally, methylating the $\mathrm{CpG}$ motifs in the $\mathrm{CpG}$ oligonucleotide resulted in a substantial reduction in the concentration of cells and cytokines in the lower respiratory tract (Fig. 6).

Results from the RNase protection assay indicate that unmethylated $\mathrm{CpG}$ motifs substantially effect mRNA transcription. Fig. 7 demonstrates that mRNA for TNF- $\alpha$, IL-1 $\beta$, IL- $1 \alpha$, and IL- 6 are increased in concentration when the mice are ex-

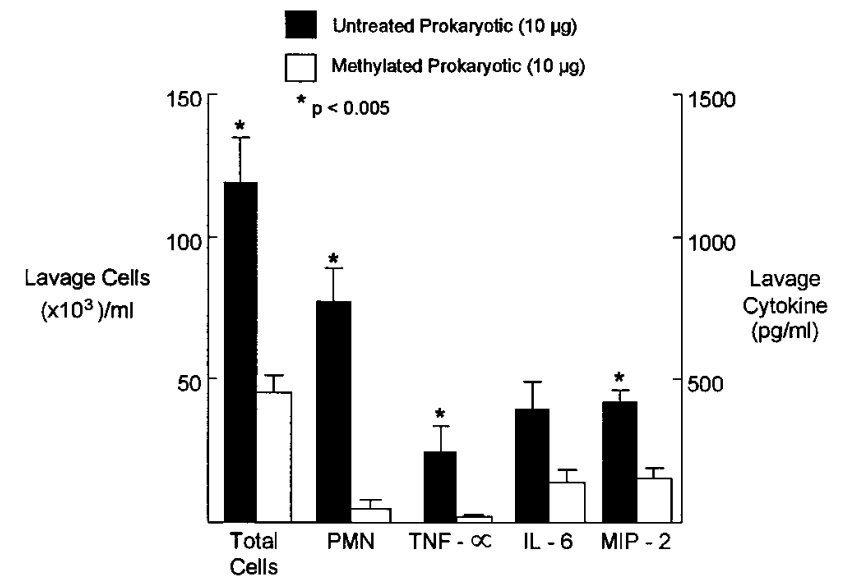

Figure 4. Concentration of total cells, PMN, and specific cytokines (TNF- $\alpha, I L-6$, and $M I P-2)$ after intratracheal instillation of untreated prokaryotic (bacterial) DNA (solid bars) and methylated prokaryotic (bacterial) DNA (open bars). Error bars, SE.

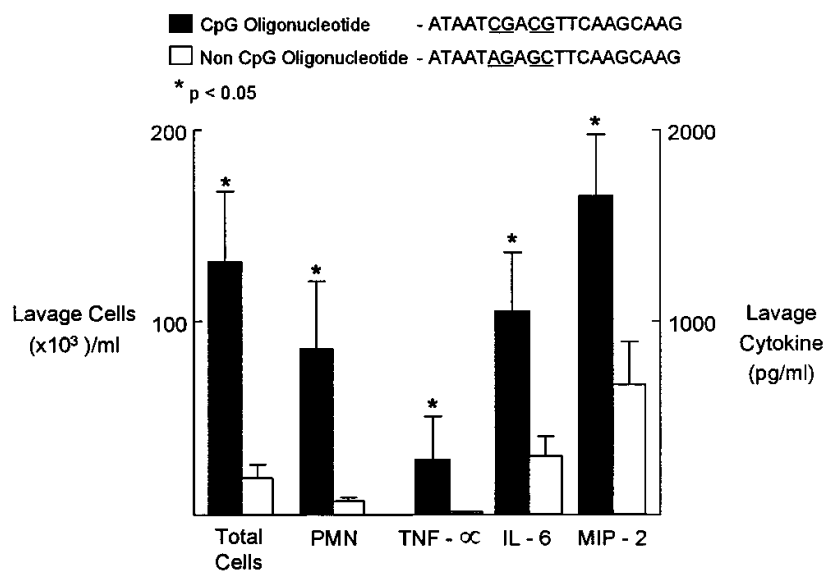

Figure 5. Concentration of total cells, PMN, and specific cytokines (TNF- $\alpha, I L-6$, and MIP-2) after intratracheal instillation of $10 \mu \mathrm{g}$ of $\mathrm{CpG}$ containing oligonucleotide (solid bars) and $10 \mu \mathrm{g}$ of non-CpG oligonucleotide (open bars). Error bars, SE.

posed to DNA containing the unmethylated CpG motifs (bacterial DNA or unmethylated $\mathrm{CpG}$ oligonucleotide) when compared to specific mRNA production following exposure to DNA without unmethylated CpG motifs (eukaryotic DNA, methylated prokaryotic DNA, non-CpG oligonucleotide, or methylated $\mathrm{CpG}$ oligonucleotide).

To assess the biological relevance of our findings, we isolated DNA from the sputum of patients with cystic fibrosis. All patients had sputum cultures yielding $P$. aeruginosa with or without additional flora. As a measure of immune activation, we assessed the ability of highly purified $P$. aeruginosa DNA to stimulate the proliferation of murine B cells using $48 \mathrm{~h}$ $\left[{ }^{3} \mathrm{H}\right]$ thymidine incorporation as described (1). Like DNA from E. coli, $P$. aeruginosa DNA triggered B cell proliferation, in contrast to calf thymus DNA, which did not (Table I). The recovery of pure DNA from the patient sputum was 0.1-2.0 $\mathrm{mg} / \mathrm{ml}$ of sputum which is similar to previous reports (22-24). As expected, the percentage of prokaryotic DNA was $\leq 1 \%$

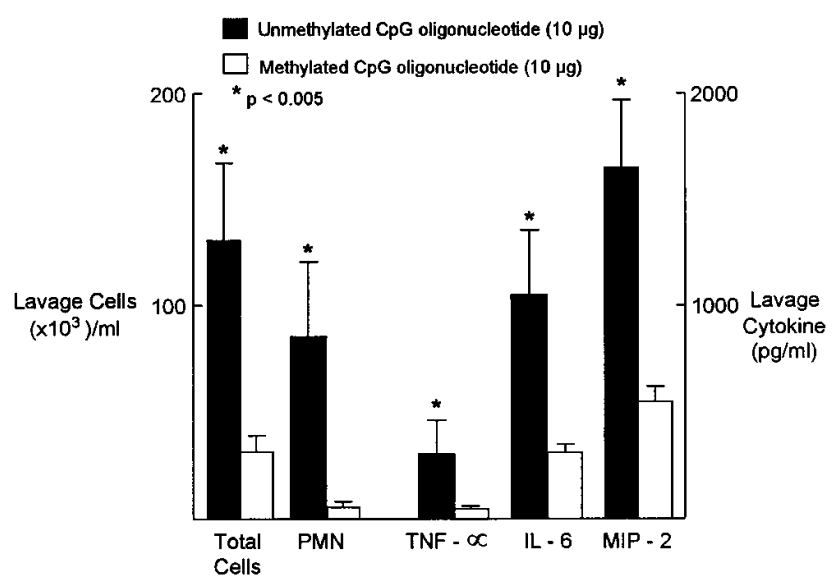

Figure 6. Concentration of total cells, PMN, and specific cytokines (TNF- $\alpha, I L-6$, and MIP-2) after intratracheal instillation of $10 \mu \mathrm{g}$ of unmethylated $\mathrm{CpG}$ oligonucleotide (solid bars) or $10 \mu \mathrm{g}$ of methylated $\mathrm{CpG}$ oligonucleotide (open bars). Error bars, SE. 


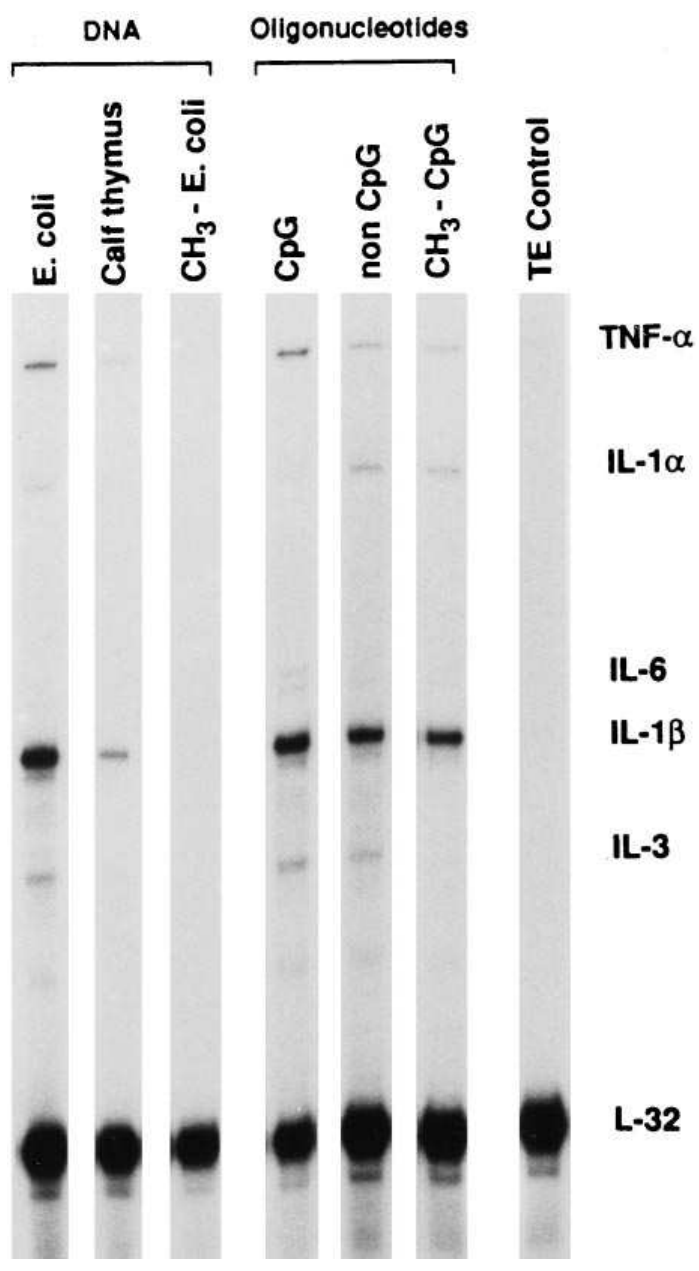

Figure 7. RNase protection assay of total RNA obtained from lungs after intratracheal instillation of either DNA containing unmethylated CpG motifs (bacterial DNA or CpG oligonucleotide) or DNA without unmethylated CpG motifs (eukaryotic DNA, methylated prokaryotic DNA, non CpG oligonucleotide, or methylated CpG oligonucleotide). Equivalent amounts of RNA were examined in each sample, as judged by the amount of L32, which encodes a ubiquitously expressed ribosome subunit protein.

of the total DNA. Intratracheal instillation of $50 \mu \mathrm{g}$ of DNA isolated from the sputum of patients with cystic fibrosis into mice resulted in substantial inflammation in the lower respiratory tract with an increase in the concentration of total cells $(81,532 \pm 32,746$ cells $/ \mathrm{ml})$ and neutrophils $(50,315 \pm 30,408$ cells/ $\mathrm{ml})$ in the lavage fluid. The concentration of cells and neutrophils in lavage fluid after intratracheal instillation of DNA derived from sputum from patients with cystic fibrosis was comparable to the inflammatory response we observed after intratracheal instillation of either prokaryotic DNA or $\mathrm{CpG}$ containing oligonucleotides.

\section{Discussion}

Our results indicate that bacterial DNA, and unmethylated CpG motifs in particular, may play an important pathogenic role in inflammatory lung disease. This conclusion is supported by our findings that bacterial DNA is proinflammatory when
Table I. Similar Induction of Lymphocyte Proliferation by E. coli and P. aeruginosa DNA

\begin{tabular}{lc}
\hline \multicolumn{1}{c}{ Treatment } & {$\left[{ }^{3} \mathrm{H}\right]$ Thymidine, cpm } \\
\hline Medium & $588 \pm 18$ \\
E. coli DNA & \\
$50 \mu \mathrm{g} / \mathrm{ml}$ & $4821 \pm 200$ \\
$\quad 5 \mu \mathrm{g} / \mathrm{ml}$ & $5782 \pm 1410$ \\
P. aeruginosa DNA & \\
$50 \mu \mathrm{g} / \mathrm{ml}$ & $5072 \pm 498$ \\
$\quad 5 \mu \mathrm{g} / \mathrm{ml}$ & $3557 \pm 587$ \\
CT DNA & \\
$50 \mu \mathrm{g} / \mathrm{ml}$ & $634 \pm 122$ \\
$5 \mu \mathrm{g} / \mathrm{ml}$ & $604 \pm 186$ \\
\hline
\end{tabular}

$\left[{ }^{3} \mathrm{H}\right]$ Thymidine assays were performed as described (1). Results are reported \pm SD. $C T$, calf thymus.

compared to eukaryotic DNA; the proinflammatory effects of bacterial DNA do not appear to be caused by endotoxin contamination and can be significantly reduced by methylation; that DNA extracted from CF sputum can reproduce the acute pulmonary inflammation; and that synthetic oligonucleotides containing embedded unmethylated $\mathrm{CpG}$ motifs are proinflammatory while oligonucleotides with methylated CpG motifs or oligonucleotides synthesized without $\mathrm{CpG}$ motifs do not cause lung inflammation. These findings imply that bacterial DNA may independently trigger lung inflammation in infectious forms of lung disease and may also play an important etiologic role in chronic forms of inflammatory lung disease.

The immunomodulatory effects of bacterial DNA may augment the inflammatory response to endotoxin. In fact, in a previous study (6) Cowdery and coworkers have shown that mice pretreated with bacterial DNA, compared with those pretreated with calf thymus DNA, had a much higher mortality when challenged with LPS. IFN- $\gamma$ appeared to mediate the enhanced LPS toxicity of bacterial DNA treated mice, since IFN- $\gamma$ was rapidly released by splenic NK cells following in vivo exposure to $E$. coli DNA and IFN- $\gamma$ knockout mice pretreated with $E$. coli DNA had a reduced toxicity to LPS. These findings suggest that bacterial DNA may induce the production of specific mediators, such as IFN- $\gamma$, which could enhance the response to LPS. We have also reported that IFN- $\gamma$ enhances the B cell activation induced by CpG DNA (25). Thus, blocking the response to bacterial DNA may substantially alter the in vivo inflammatory response to LPS.

These findings could have a profound effect on the way we think about chronic inflammatory lung diseases, such as asthma, chronic obstructive lung disease, cystic fibrosis, and pulmonary fibrosis. If inhaled or resident bacterial DNA is proinflammatory and/or enhances the toxicity of LPS, then simply killing bacteria is insufficient. DNA from dead bacteria would still be present and could induce or promote an inflammatory response. Strategies would have to be developed to minimize bacterial growth, enhance bacterial clearance, degrade bacterial DNA, and block the stimulatory effects of bacterial DNA. In fact, our results indicate that DNA derived from the sputum of patients with cystic fibrosis initiates an inflammatory response in the lower respiratory tract.

As basic research leads to the identification of abnormali- 
ties in gene expression predisposing to pulmonary diseases, there is increasing interest in using the powerful techniques of gene therapy to restore deficient gene expression, or to express therapeutic genes. The approaches currently being used or considered for pulmonary delivery of DNA include viral vectors and nonviral DNA delivery systems such as liposomes. Some of these approaches are already known to be associated with unwanted immune activation, the nature and causes of which have been incompletely studied. In this regard, it is noteworthy that the immune effects of DNA vaccines have recently been reported to result from the presence of $\mathrm{CpG}$ motifs (26).

The oligonucleotides used in the present studies were selected because their stimulatory effects on lymphocytes were representative of the large number of different oligonucleotides we compared in our preliminary studies. To our knowledge, there have been no studies that have demonstrated any preferential exposure of these or other sequences during nuclease digestion of prokaryotes. We do not believe that structural constraints are a major limitation to the immune activation by bacterial DNA, since we observe only a modest difference in the level of lymphocyte activation by doublestranded vs. single-stranded bacterial DNA (1) or bacterial DNA digested with various restriction enzymes, including enzymes with four base recognition sites, where the average length will be 256 bp (unpublished data). Other investigators have shown that bacterial DNA is taken up by monocytes and lymphocytes, and degraded into oligonucleotides $(12,27)$. Thus the intracellular forms of the DNAs used in our studies are likely to be identical.

The present studies show that bacterial DNAs or synthetic oligodeoxynucleotides containing unmethylated $\mathrm{CpG}$ dinucleotides induce pulmonary inflammation. These studies suggest that pulmonary gene therapy techniques involving the delivery of DNA with CpG motifs will likely cause local immune activation and cytokine secretion. Further studies will need to be performed to determine whether such a DNA-mediated inflammatory response can be avoided by modification of these gene delivery systems.

\section{Acknowledgments}

Dr. Krieg is a Veterans Affairs career development awardee and AeKyung Yi is an Arthritis Foundation postdoctoral fellow. The authors thank Dr. M. Hobbs for providing probes for RNase protection assay.

This study was supported by grants from the Department of Veterans Affairs (Merit Review), the Cystic Fibrosis Foundation, the University of Iowa Diabetes Endocrinology Research Center (DK 25295), and the National Institute of Environmental Health Sciences (ES06537, ES00203, and ES05605).

\section{References}

1. Krieg, A.M., A.K. Yi, S. Matson, T.J. Waldschmidt, G.A. Bishop, R. Teasdale, G.A. Koretzky, and D.M. Klinman. 1995. CpG Motifs in bacterial DNA trigger direct B-cell activation. Nature (Lond.). 374:546-549.

2. Messina, J.P., G.S. Gilkeson, and D.S. Pisetsky. 1991. Stimulation of in vitro murine lymphocyte proliferation by bacterial DNA. J. Immunol. 147: 1759-1764.

3. Klinman, D.M., A.K. Yi, S.L. Beaucage, J. Conover, and A. Krieg. 1996. CpG Motifs present in bacterial DNA rapidly induce lymphocytes to secrete in- terleukin 6, interleukin 12, and interferon $\gamma$. Proc. Natl. Acad. Sci. USA. 93: 2879-2883.

4. Yi, A.-K., P. Hornbeck, D.E. Lafrenz, and A.M. Krieg. 1996. CpG DNA rescue of murine B lymphoma cells from anti-IgM induced growth arrest and programmed cell death is associated with increased expression of c-myc and bcl-XL. J. Immunol. 157:4918-4925.

5. Yi, A.-K., D.M. Klinman, T.L. Martin, S. Matson, and A.M. Krieg. 1996. Rapid immune activation by $\mathrm{CpG}$ motifs in bacterial DNA: systemic induction of IL-6 transcription through an antioxidant-sensitive pathway. J. Immunol. 157:5394-5402.

6. Cowdery, J.S., J.H. Chace, and A.M. Krieg. 1996. Bacterial DNA Induces NK cells to produce Interferon-gamma in vivo and increase the toxicity of lipopolysaccharides. J. Immunol. 156:4570-4575.

7. Ballas, Z.K., W.L. Rasmussen, and A.M. Krieg. 1996. Induction of natural killer activity in murine and human cells by $\mathrm{CpG}$ motifs in oligodeoxynucleotides and bacterial DNA. J. Immunol. 157:1840-1845.

8. Tokunaga, T., H. Yamamoto, S. Shimada, H. Abe, T. Fukuda, Y. Fujisawa, Y. Furutani, O. Yano, T. Kataoka, T. Sudo, et al. 1984. Antitumor activity of deoxyribonucleic acid fraction from mycobacterium bovis GCG. I. Isolation, physicochemical characterization, and antitumor activity. J. Natl. Cancer Inst. 72:955-962.

9. Kuramoto, E., O. Yano, Y. Kimura, M. Baba, T. Makino, S. Yamamoto, T. Yamamoto, T. Kataoka, and T. Tokunaga. 1992. Oligonucleotide sequences required for natural killer cell activation. Jpn. J. Cancer Res. 83:1128-1131.

9a. Chace, J.H., N.A. Hooker, K.L. Mildenstein, A.M. Krieg, and J.S. Cowdery. 1997. Bacterial DNA-induced NK cell IFN- $\gamma$ production is dependent on macrophage secretion of IL-12. Clin. Immunol. Immunopathol. In press.

10. Bird, A.P. 1987. CpG islands as gene markers in the vertebrate nucleus. Trends Genet. 3:342-347.

11. Krieg, A.M. 1996. An innate immune defense mechanism based on the recognition of CpG motifs in microbial DNA. J. Lab. Clin. Med. 128:128-133.

12. Bennet, R.M., G.T. Gabor, and M.M. Merritt. 1985. DNA binding to human leukocytes. Evidence for a receptor-mediated association, internalization, and degradation of DNA. J. Clin. Invest. 76:2182-2190.

13. Zhao, Q., X. Song, T. Waldschmidt, E. Fisher, and A.M. Krieg. 1996. Oligonucleotide uptake in human hematopoietic cells is increased in leukemia and is related to cellular activation. Blood. 88:1788-1795.

14. Krieg, A.M. 1995. Uptake and localization of phosphodiester and chimeric oligodeoxynucleotides in normal and leukemic primary cells. In Delivery Strategies for Antisense Oligonucleotide Therapeutics. S. Akhtar, editor. CRC Press, Inc., Boca Raton, FL. 177-190.

15. Jagielo, P.J., P.S. Thorne, J.A. Kern, T.J. Quinn, and D.A. Schwartz. 1996. Role of endotoxin in grain dust-induced lung inflammation in mice. Am. J. Physiol. (Lung Cell. Mol. Physiol.) 270:L1052-L1059.

16. Goldberg, J.B., and D.E. Ohman. 1984. Cloning and Expression in Pseudomonas aeruginosa of a Gene Involved in the Production of Alginate. $J$. Bacteriol. 158:1115-1121.

17. Leeper-Woodford, S.K., P.D. Carey, K. Byrne, C. Blocher, J.H. Sugerman, and A.A. Fowler. 1991. TNF: $\alpha$ and $\beta$ subunits appear in the circulation during onset of sepsis-induced lung injury. Am. Rev. Respir. Dis. 143:10761082 .

18. Chomczynski, P., and N. Sacchi. 1987. Single-step method of RNA isolation. Anal. Biochem. 162:156-159.

19. Kedzierski, W. 1991. Removal of DNA template from RNA transcription mixtures. Biotechniques. 10:210-214.

20. Hobbs, M.V., W.O. Weigle, D.J. Noonan, B.E. Torbett, R.J. McEvilly, R.J. Koch, G.J. Cardenas, and D.N. Ernst. 1993. Patterns of cytokine gene expression by $\mathrm{CD}^{+} \mathrm{T}$ cells from young and old mice. J. Immunol. 150:3602-3614.

21. Rosner, B. 1980. Fundamentals of Biostatistics (3rd ed.). PWS-Kent, Boston. 375 pp.

22. Chernick, W.S., and G.J. Barbero. 1959. The composition of pulmonary secretions from patients with and without cystic fibrosis. Pediatrics. 24:739-745.

23. Potter, J., L.W. Matthews, J. Lemm, and J.S. Spector. 1960. Studies on pulmonary secretions. Am. J. Dis. Child. 100:493-495.

24. Matthews, L.W., S. Spector, J. Lemm, and J.L. Potter. 1963. Composition of tracheobronchial secretions in cystic fibrosis of the pancreas and bronchiectasis. Am. Rev. Respir. Dis. 88:199-204.

25. Yi, A.-K., J.H. Chace, J.S. Cowdery, and A.M. Krieg. 1996. IFN-y promotes IL-6 and IgM secretion in response to CpG motifs in bacterial DNA and oligodeoxynucleotides. J. Immunol. 156:558-564.

26. Sato, Y., M. Roman, H. Tighe, D. Lee, M. Corr, M.-D. Nguyen, G.J. Silverman, M. Lotz, D.A. Carson, and E. Raz. 1996. Immunostimulatory DNA sequences necessary for effective intradermal gene immunization. Science (Wash. DC). 273:352-354

27. Rozenberg-Arska, M., J.A.G. van Strijp, W.P.M. Hoekstra, and J. Verhoef. 1984. Effect of human polymorphonuclear and mononuclear leukocytes on chromosomal and plasmid DNA of Escherichia coli. Role of acid DNase. J. Clin. Invest. 73:1254-1262. 